\title{
Sonographic Aspects of Splenic Torsion Due to Abdominal Eventration in a Dog
}

\author{
Nathalia Brant Malta Salgueiro', Antonio Carlos Cunha Lacreta Junior', \\ Ana Carolina Giudice Tavares' \& Mariana Avelino de Souza Santos ${ }^{2}$
}

\begin{abstract}
Background: The splenic torsion is a rare condition in dogs, especially when it is not associated with gastric dilatation and volvulus. Abdominal ultrasonography has been reported as an accurate diagnostic method in cases of splenic torsion suspicions. Splenomegaly, decreased echogenicity of the parenchyma of the spleen and hypoechoic appearance or "lace" are suggestive sonographic findings, although the definitive diagnosis is given through exploratory laparotomy. This study reports a case of splenic torsion followed by abdominal trauma and eventration in a dog, highlighting the importance of the ultrasound examination.

Case: An adult dog without a defined breed pattern that weighed $8.6 \mathrm{~kg}$ was referred to the Veterinary Hospital of the Federal University of Lavras (Universidade Federal de Lavras - UFLA) with a history of trauma caused by having been run over by a car $24 \mathrm{~h}$ earlier. The animal exhibited right inguinal region swelling with hematoma and a loss of local muscular tension. An abdominal ultrasound indicated that the spleen was displaced to the right inguinal region and that a portion of the spleen was included in the animal's abdominal eventration. The spleen possessed an irregular surface with increased dimensions and diffusely decreased echogenicity and multiple parallel echogenic lines (in the reticular aspect). Abrupt differences in the echogenic textures of the spleen were identified in certain images. Color Doppler assessments revealed no blood flow. Based on the aforementioned ultrasound findings, an exploratory laparotomy was indicated. The laparotomy confirmed the presence of right inguinal abdominal muscle rupture with dislocation, eventration, and splenic torsion.

Discussion: Splenic torsion may be most frequently reported in cases involving large and giant male dogs because this condition is typically related to dilatation syndrome and gastric volvulus, which are more prevalent among large and giant male dogs than among other dogs. Although these etiological factors should be considered, in the case examined in this study, the patient most likely suffered from splenic torsion caused by abdominal trauma, which resulted in the rupture of the gastrosplenic and splenocolic ligaments and the splenic vessels and thereby created circumstances conducive to splenic eventration and torsion. The sonographic features of splenic torsion in dogs include marked splenomegaly, a hypoechoic or diffuse anechogenic pattern that indicates the presence of vascular congestion, and sinusoidal dilatation separated by small linear echoes that represent dilated vessels. In cases of splenic torsion, two-dimensional ultrasonographic images may reveal an enlarged spleen with a hypoechoic echotexture and a hyperechoic triangle between the veins and the splenic parenchyma continuous to the hyperechoic mesentery. The sonographic findings observed in the patient examined in this study were similar to the findings described in the published literature and consistent with the results reported by the other authors. Although extensive literature reports have described the sonographic aspects of splenic torsion in dogs, this disease remains uncommon. Moreover, no prior reports have described splenic torsion secondary to concurrent abdominal trauma, displacement, and eventration; thus, the case examined in this study is unprecedented, and the ultrasonographic aspects observed in this case should be considered.
\end{abstract}

Keywords: dogs, injuries, spleen, ultrasonography, Doppler. 


\section{INTRODUCTION}

The splenic torsion is considered to be a rare condition in dogs $[7,12]$. It occurs due to hypermotility of the organ owing to ligamentous laxity, which may be congenital or acquired. It may be primary when happening alone or in combination with dilation and gastric volvulus, the latter being the most common cause. The occurrence of this disease is often in its acute form. The chronic form may have nonspecific clinical manifestations which makes the diagnosis difficult and challenging.

Ultrasonography is a reliable method for diagnosis of splenic torsion. It is a noninvasive and an elucidative method that allows detection of changes in the parenchyma, as well as visualization of the size and the location of the organ [3].

The purpose of this case report is to draw the attention of clinicians and veterinary surgeons to the possibility of splenic torsion followed by abdominal trauma, especially those which are associated with eventration; emphasizing the importance and the findings of ultrasound examination.

\section{CASE}

An adult male dog without a defined breed pattern that weighed $8.6 \mathrm{~kg}$ was referred to the Veterinary Hospital of the Federal University of Lavras (Universidade Federal de Lavras - UFLA) with a history of trauma caused by having been run over by a car $24 \mathrm{~h}$ earlier. Physical examination of the animal revealed right inguinal region swelling with hematoma and loss of local muscle tension (eventration), pale mucous membranes, and walking difficulties caused by abdominal discomfort.

Abdominal ultrasonography was performed with an Esaote MyLab ${ }^{\text {TM }} 40$ instrument equipped with multifrequency linear (3.5-10 MHz) and microconvex (5-8 MHz) transducers. Ultrasonographic examination indicated that the spleen was shifted to the right inguinal region and that a portion of the spleen was included in the animal's abdominal eventration. This organ possessed an irregular surface with increased dimensions and diffusely decreased echogenicity. Abrupt differences in the echogenic textures of the spleen were identified in certain images (Figure 1). In particular, multiple parallel echogenic lines (in the reticular aspect) were visible in the head of the spleen, which exhibited a coarse texture (Figure 2), whereas echogenicity decreased and granulation became finer as ultrasonographic scans progressed through the middle of the body of the spleen toward the tail. Color Doppler assessments revealed no blood flow (Figure 3).

An abdominal cavity scan indicated that a small quantity of free fluid and an irregular hyperechoic formation existed in the spleen region adjacent to the cranial edge of the left kidney; these phenomena were consistent with the presence of a clot (Figure 4). No notable abnormalities were detected in other organs, and no abdominal muscle discontinuity was observed in further ultrasound examinations.

Based on the aforementioned ultrasound findings, an exploratory laparotomy was indicated. This laparotomy confirmed the presence of right inguinal abdominal muscle rupture with dislocation, eventration, and splenic torsion. It was observed that the spleen was only connected to a single blood vessel. Total splenectomy and abdominal wall repair were performed, and the animal recovered well without further clinical complications.

\section{DISCUSSION}

The patient described in this study is a male dog. Splenic torsions may be more prevalent in males than in females $[11,13,17]$. Although splenic torsion most commonly arises in large and giant-breed dogs and in deep-chested animals $[2,4,18,19]$, the dog examined in this study was small. Certain reports have addressed the unusual phenomenon of splenic torsion in small and medium-sized animals [15]. Splenic torsion may be most frequently reported in cases involv-

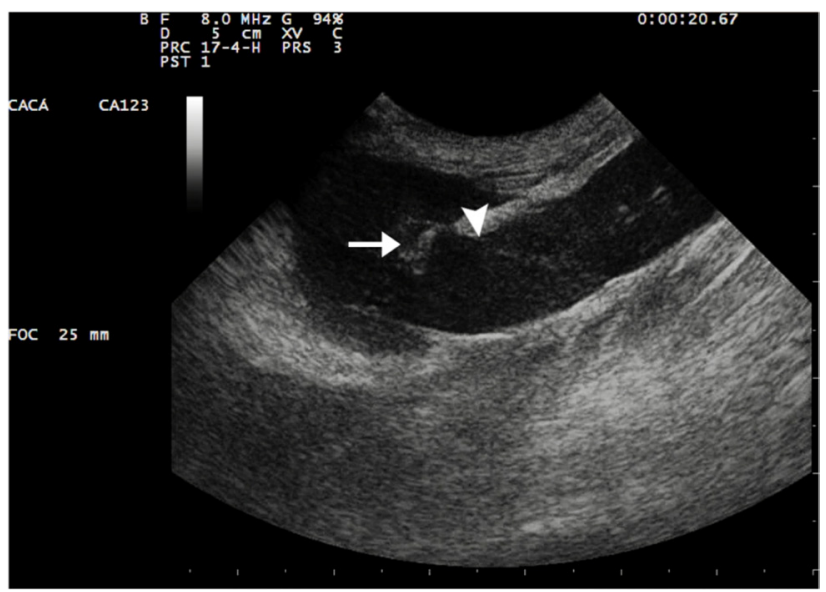

Figure 1. Ultrasound image of the spleen in longitudinal section. The echogenicity is diffusely reduced with the presence of mild amount of free fluid (arrow). Notice that there is an abrupt difference in the echogenic texture (arrow head). 


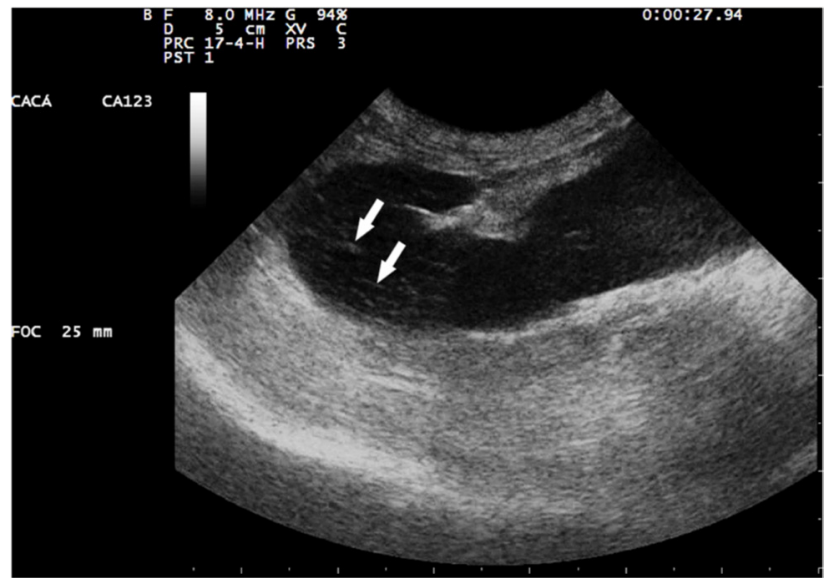

Figure 2. Parallel echogenic lines (reticular aspect) can be found in the head of the spleen (arrows).

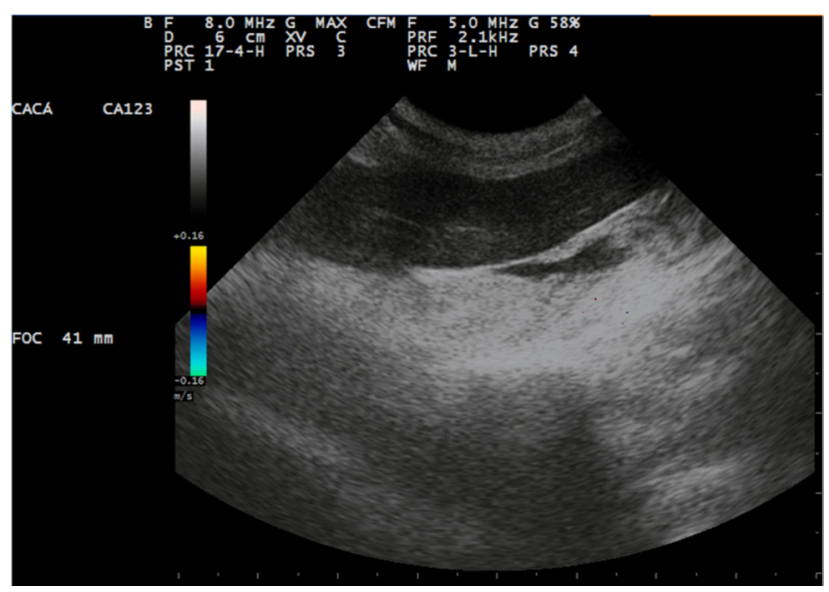

Figure 3. Ultrasound image of the spleen in longitudinal section. The echogenicity is diffusely reduced. Color Doppler assessments revealed no blood flow.

ing large and giant male dogs, because this condition is typically related to dilatation syndrome and gastric volvulus, which are more prevalent among large and giant male dogs than among other dogs. Although these etiological factors should be considered, in the case examined in this study, the patient most likely suffered from splenic torsion caused by abdominal trauma, which resulted in the rupture of the gastrosplenic and splenocolic ligaments and the splenic vessels and thereby created circumstances conducive to splenic eventration and torsion. This process was independent of the animal's sex or breed. Thus, in animals with a history of being run over, increased abdominal volume, and palpable eventration site content, the possibility of splenic eventration should be considered, and splenic torsion may have occurred.

The sonographic features of splenic torsion in dogs include marked splenomegaly, a hypoechoic or diffuse anechogenic pattern that indicates the presence of vascular congestion, and sinusoidal dilatation separated by small linear echoes that represent dilated vessels $[7,16,18]$. In cases of splenic torsion, twodimensional ultrasonographic images may reveal an enlarged spleen with a hypoechoic echotexture and a hyperechoic triangle between the veins and the splenic parenchyma continuous to the hyperechoic mesentery [11]. The sonographic findings observed in the patient examined in this study were similar to the findings described in the published literature. Echogenicity may be normal in cases of splenic torsion [6,11]. However, this phenomenon was not observed in the case examined in the current report.

Although the aforementioned ultrasonographic aspects are suggestive of splenic torsion, these characteristics can also be observed in other diseases [14]. Ultrasonographic aspects of the spleens of dogs with babesiosis are similar to the ultrasonographic aspects of the spleens of animals with splenic torsion [5] and animals with diffuse splenic infarction [10]. This similarity between the ultrasonographic aspects of splenic torsion and the ultrasonographic aspects of other diseases constitutes a limitation on the use of ultrasound for obtaining definite diagnoses of splenic torsion; as a result, these diagnoses should be regarded as differential diagnoses.

In the examined case, in addition to the ultrasonographic aspects of splenic torsion that have been described in the literature, an abrupt change in the echogenic texture in the middle regions of the body of the spleen was observed. This well-marked and visible

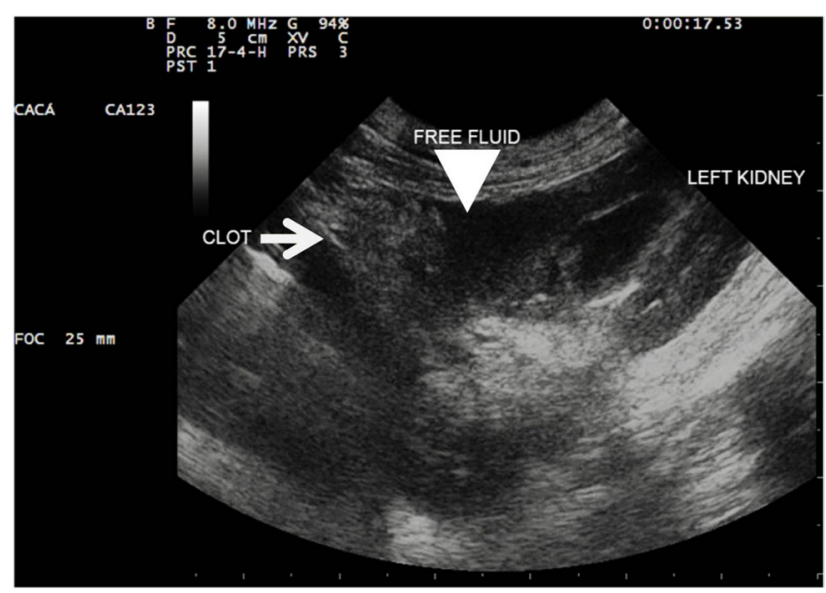

Figure 4. Ultrasound image of the spleen and left kidney region, where it is possible to visualize irregular echogenic structure cranial to the kidney, compatible with a clot (arrow) and a slight amount of free fluid (arrowhead). It was not possible to visualize the spleen in its usual topographic region. 
change may have reflected on regional stasis of the blood in splenic veins or even on an interruption in the irrigation of the spleen in this region; these phenomena may have been caused by the rupture of splenic vessels, which was observed during the surgical procedures described above. Because this ultrasonographic aspect has not been mentioned in the published literature, this characteristic may represent an isolated finding that should be investigated further in other cases of splenic torsion.

The use of color Doppler is necessary for hemodynamic assessment of the spleen, because color Doppler provides observable evidence of the absence of hemodynamic flow in cases of splenic torsion $[14,16,18]$. The ultrasonographic aspects observed during color Doppler evaluations of the patient corroborated the ultrasonographic aspects found in scientific literature $[14,16,18]$. Because the sonographic aspects observed in two-dimensional examinations are merely suggestive of the presence of splenic torsion, Doppler ultrasonography is an important approach that contributes to the definitive diagnosis of this condition.

Dilation of splenic veins in the hilum region can be observed in cases of splenic torsion $[9,16]$. Perivascular hyperechogenic triangle could also occur in the same region $[2,7,11]$. In addition, echogenic areas that represent thrombi can be observed within splenic veins $[8,16,17]$. In contrast to the findings of previously published papers, in the case examined in the current study, sonographic features suggestive of vascular dilatation were not observed; however, triangular hyperechoic areas were present in the splenic hilum region. It appears that these observations reflected the near-complete disruption of splenic vessels and ligaments in the examined animal; in particular, an exploratory laparotomy revealed that the spleen only remained connected to only a single blood vessel.

The presence of free fluid adjacent to the spleen can be observed in certain cases of splenic torsion $[16,18]$. This free fluid was visible in the animal examined in the current study. In addition to free fluid, abdominal clots were also detected; these clots were attributed to the effects of abdominal trauma and subsequent bleeding.

Computed tomography (CT) and magnetic resonance imaging (MRI) are the most accurate approaches for the definitive diagnosis of splenic torsion. These methods are widely utilized to assess human patients [1] but are rarely employed in veterinary medicine. In Brazil, CT and MRI cannot be performed in veterinary contexts due to the high cost and low accessibility of these techniques; in particular, few veterinary centers own the necessary equipment for these diagnostic techniques.

Thus, deep ultrasonography is required to assess cases of suspected splenic torsion. Ultrasonography is an imaging approach that is relatively appropriate for the actual context of veterinary medicine in Brazil, and the costs of ultrasonography are lower than the costs of CT and MRI. The sonographer's experience and knowledge are critical to diagnostic success, particularly in the absence of equipment with Doppler capabilities.

Although extensive literature reports have described the sonographic aspects of splenic torsion in dogs, this condition remains uncommon. Moreover, no prior reports have described splenic torsion secondary to concurrent abdominal trauma, displacement, and eventration; thus, the case examined in this study is unprecedented, and the ultrasonographic aspects observed in this case should be considered.

According to the current report, ultrasonographic examination was an effective method for generating a predictive diagnosis of splenic torsion in the examined dog and establishing a surgical treatment plan. The observed B-mode ultrasonographic aspects are merely suggestive of splenic torsion, which constitutes a limitation of this type of examination; however, in cases of acute torsion, the presence of hyperechoic triangles in the splenic hilum region is a strong indicator of this condition. Doppler evaluation may be employed to strengthen confidence in a diagnosis of splenic torsion, which can be confirmed by exploratory laparotomy. Veterinarians should be aware of the conditions that lead to acute abdomen in dogs; in particular, in cases of abdominal trauma, veterinarians should add splenic torsion to the list of differential diagnoses, particularly if ultrasonographic examinations reveal splenic displacement and eventration.

Declaration of interest. The authors report no conflicts of interest. The authors alone are responsible for the content and writing of the paper.

\section{REFERENCES}

1 Arda K., Kizilkanat K., Celik M. \& Turkalp E. 2004. Intermittent torsion of a wandering spleen in a child: The role of MRI in diagnosis. Journal of the Belgian Society of Radiology. 87: 70-72.

2 Armbrust L. 2012. Baço. In: O’Brien R. \& Barr F. (Eds). Manual de diagnóstico por imagem abdominal de cães e 
gatos. São Paulo: Roca, pp.205-217.

3 Bandinelli M.B., Pavarini S.P., Oliveira E.C., Gomes D.C., Cruz C.E.F. \& Driemeier D. 2011. Estudo retrospectivo de lesões em baços de cães esplenectomizados: 179 casos. Pesquisa Veterinária Brasileira. 31(8): 697-701.

4 Fossum T.W. 2008. Cirurgia do sistema hemolinfático. In: Cirurgia de pequenos animais. Rio de Janeiro: Elsevier, pp.617-634.

5 Fraga E., Barreiro J.L., Goicoa A., Espino L., Fraga G. \& Barreir A. 2011. Abdominal ultrasonographic findings in dogs naturally infected with babesiosis. Veterinary Radiology \& Ultrasound. 52(3): 323-329.

6 Goldsmid S.E., Davis P. \& Pechman R. 1994. Successful derotation of a splenic torsion in a racing greyhound. Journal of Small Animal Practice. 35: 112-115.

7 Hecht S. 2011. Baço. In: Penninck D. \& D’Anjou M.A. (Eds). Atlas de ultrassonografia de pequenos animais. Rio de Janeiro: Guanabara Koogan, pp.261-278.

8 Kealy J.K., McAllister H. \& Graham J.P. 2012. Radiologia e Ultra-sonografia do Cão e do Gato. 5.ed. Rio de Janeiro: Elsevier, 580p.

9 Konde L.J., Wrigley R.H., Lebel J.L., Park R.D., Pugh C. \& Finn S. 1989. Sonographic and radiographic changes associated with splenic torsion in the dog. Veterinary Radiology. 30(1): 41-45.

10 Larson M.M. 2013. The Liver and Spleen. In: Textbook of Veterinary Diagnostic Radiology. 6th edn. St. Louis: Saunders, pp.679-704.

11 Mai W. 2006. The hilar perivenous hyperechoic triangle as a sign of acute splenic torsion in dogs. Veterinary Radiology \& Ultrasound. 47(5): 487-491.

12 Mannion P. 2010. Fígado e Baço. In: Ultrassonografia de pequenos animais. Rio de Janeiro: Revinter, pp.50-80.

13 Neath P.J., Brockman D.J. \& Saunders H.M. 1997. Retrospective analysis of 19 cases of isolates torsion of the splenic pedicle in dogs. Journal of Small Animal Practice. 38: 387-392.

14 Nyland T.G., Mattoon J.S, Herrgesell E.J. \& Wisner E.R. 2005. Baço. In: Nyland T.G. \& Mattoon J.S. (Eds). Ultra-som diagnóstico em pequenos animais. São Paulo: Roca, pp.131-146.

15Ohta H., Takagi S., Murakami M., Sasaki N., Yoshikawa M., Nakamura K., Hwang S.J, Yamasaki M. \& Takiguchi M. 2009. Primary Splenic Torsion in a Boston Terrier. Journal Veterinary Medicine Science. 71(11): 1533-1535.

16 Patsikas M.N., Papazoglou L.G., Brellou G.D., Papadopoulou P.L. \& Dessiris A.K. 2005. Diagnostic challenge. Depression, anorexia and abdominal pain in a young dog with an abdominal mass. Australian Veterinary Journal. 83(8): 29-30.

17 Saunders H.M., Neath P.J. \& Brockman D.J. 1998. B-mode and Doppler utrasound imaging of the spleen with canine splenic torsion: a retrospective evaluation. Veterinary. Radiology and Ultrasound. 39: 349-353.

18 Tannouz V.G.S. 2004. Baço. In: Carvalho C.F. (Ed). Ultra-sonografia em Pequenos Animais. São Paulo: Roca, pp.85-99.

19 Tillson D.M. 2003. Hemolymphatic system. In: Slatter D. (Ed). Textbook of small animal surgery. 3rd edn. Philadelphia: Elsevier Science, pp.1046-1062. 